\title{
Establishment of a novel platform cell line for efficient and precise evaluation of $\mathrm{T}$ cell receptor functional avidity
}

\author{
Soyoko Morimoto ${ }^{1}$, Fumihiro Fujiki², Kenta Kondo ${ }^{3}$, Hiroko Nakajima ${ }^{2}$, Yoshiki \\ Kobayashi ${ }^{3}$, Miki Inatome ${ }^{3}$, Nao Aoyama ${ }^{3}$, Yuya Nishida ${ }^{3}$, Akihiro Tsuboi ${ }^{1}$, Yoshihiro \\ Oka $^{4,5,6}$, Sumiyuki Nishida5 ${ }^{5}$ Jun Nakata ${ }^{1}$, Naoki Hosen ${ }^{4}$, Yusuke Oji $^{3}$ and Haruo \\ Sugiyama² \\ ${ }^{1}$ Department of Cancer Immunotherapy, Osaka University Graduate School of Medicine, Osaka, Japan \\ ${ }^{2}$ Department of Cancer Immunology, Osaka University Graduate School of Medicine, Osaka, Japan \\ ${ }^{3}$ Department of Functional Diagnostic Science, Osaka University Graduate School of Medicine, Osaka, Japan \\ ${ }^{4}$ Department of Cancer Stem Cell Biology, Osaka University Graduate School of Medicine, Osaka, Japan \\ ${ }^{5}$ Department of Respiratory Medicine and Clinical Immunology, Osaka University Graduate School of Medicine, Osaka, Japan \\ ${ }^{6}$ Department of Immunopathology, Immunology Frontier Research Center (World Premier International Research Center), \\ Osaka University, Osaka, Japan
}

Correspondence to: Fumihiro Fujiki, email: fu-fuji@sahs.med.osaka-u.ac.jp Keywords: WT1; TCR; TCR functional avidity; TCR-engineered T-cell therapy

Received: May 22, $2018 \quad$ Accepted: September 10, $2018 \quad$ Published: September 25, 2018

Copyright: Morimoto et al. This is an open-access article distributed under the terms of the Creative Commons Attribution License 3.0 (CC BY 3.0), which permits unrestricted use, distribution, and reproduction in any medium, provided the original author and source are credited.

\section{ABSTRACT}

Adoptive T-cell therapy with $T$ cell receptor (TCR) -engineered $T$ cells is an attractive strategy for cancer treatment and the success in this therapy is dependent on the functional avidity of the transduced TCRs against targeted tumor antigens. Therefore, the establishment of the methodology of the efficient and precise evaluation of TCR functional avidity has been awaited. Here, we show a novel platform cell line, named 2D3, which enables the functional avidity of transduced TCRs to be evaluated efficiently and precisely. In the 2D3, the precise TCR functional avidity of transduced TCRs is easily evaluable by the expression of green fluorescent protein (GFP) reporter gene driven by nuclear factor of activated T cells (NFAT) activation via TCR signaling. Four different TCRs of HLA-A*24:02-restricted Wilms' tumor gene 1 (WT1)-specific CD8 ${ }^{+}$cytotoxic T lymphocytes (CTLs) were transduced into 2D3 cells and the functional avidities of these four TCRs were evaluated. The evaluated functional avidity of these TCRs positively correlated with cell proliferation, cytokine production, and WT1-specific cytotoxicity of the TCR-transduced CD8 ${ }^{+} \mathbf{T}$ cells in response to WT1 antigen. These results showed that 2D3 cell line was a novel and stable tool useful for the efficient and precise evaluation of the functional avidity of isolated and transduced TCRs in developing TCR-based immunotherapy.

\section{INTRODUCTION}

Adoptive immunotherapy using tumor-associated antigen (TAA)-specific $\mathrm{CD}^{+}$cytotoxic $\mathrm{T}$ lymphocytes (CTLs) and/or $\mathrm{CD}^{+}$helper $\mathrm{T}$ (Th) cells can induce the regression of large established tumor in not only mouse models but also cancer patients [1-3]. These preclinical and clinical evidences encourage us to develop T-cell adoptive immunotherapy using genetically engineered $\mathrm{T}$ cells that are transduced with a T-cell receptor (TCR) gene specific for TAA. Furthermore, more recent studies have demonstrated that neo-antigens, which are generated from passenger mutations, would be promising targets for the engineered TCR-T cell therapy $[4,5]$. 
In parallel with seeking for good targets from TAAs and neo-antigens by genome-wide approaches [6-8], novel methods analyzing huge number of TCR repertoire $[9,10]$ and efficiently isolating TCR gene from a singlecell [11] have been developed. Unfortunately, not all isolated TCRs can sufficiently elicit anti-tumor immunity. Hence, development of a new method for the precise and efficient evaluation of the isolated TCRs has been awaited for the prediction of clinical response in the engineered TCR-T cell adoptive therapy.

TCR affinity, TCR avidity, and functional avidity are known as an indicator to predict the in vitro/in vivo properties and behavior of the TCR-transduced $\mathrm{T}$ cells [12-14]. TCR affinity, which is defined as the binding-strength of TCR molecules to peptide-major histocompatibility complex (pMHC), is often used for this prediction beyond TCR's specificity because it can standardize the strength of TCR binding to pMHC by using a numerical value (ie, $\mathrm{K}_{\mathrm{D}}$ value). However, purified soluble TCR $\alpha / \beta$ complex is needed for calculating TCR affinity. It is, therefore, not feasible for screening a large number of candidate TCRs. In addition, it has been shown that TCR affinity is sometimes not consistent with actual T cell function $[12,14]$. On the other hand, both TCR avidity (which is usually measured by pMHC tetramers) and functional avidity (which is assessed using a titrated concentration of antigen peptide with antigenpresenting cells) are correlated with in vitro cytotoxicity and in vivo anti-tumor activity in TCR-transduced $\mathrm{T}$ cells $[12,15]$. Since preparation of large sets of tetramer for candidate TCRs is difficult in terms of cost, time, and effort, assessment of functional avidity must be the most adequate and feasible approach for screening of TCRs capable of provoking a good clinical response in engineered T-cell adoptive immunotherapy.

Functional avidity is assessed by phosphorylation of linker for activation of $\mathrm{T}$ cells (LAT) and extracellular signal-regulated kinase (ERK), calcium influx, and cytokine release after the stimulation with a titrated concentration of antigen peptide. Compared to TCR affinity, functional avidity is a relative indicator and easily influenced by various factors such as CD8/CD4 coreceptors and TCR clustering (ie, quantity of TCR/CD3 molecules and where and how TCR-pMHC interaction are formed) $[13,16]$. Therefore, the use of primary $\mathrm{T}$ cells for the assessment of precise functional avidity is inappropriate because they are heterogeneous and express endogenous TCRs that cause incorrect TCR clustering by mispairing with transduced TCRs [17] and competing for CD3 molecules [18].

In this study, we describe a novel platform cell line, named 2D3, for efficient and precise evaluation of TCR functional avidity. 2D3 cells are endogenous TCRnull and CD8-positive and can express green fluorescent protein (GFP) through transcription factor nuclear factor of activated $\mathrm{T}$ cells (NFAT) that is activated by TCR signaling. Therefore, the establishment of 2D3 cells enabled us to selectively analyze the functional avidity of appropriately transduced TCRs by using GFP expression as a marker.

Thus, 2D3 cell line should be a good tool useful for the evaluation of the functional avidity of isolated and transduced TCRs and prediction of the TCR-transduced $\mathrm{T}$ cell function in developing effective adoptive T-cell immunotherapy against cancer.

\section{RESULTS}

\section{Establishment of $2 \mathrm{D} 3$ cell line by the transduction of hCD8 and NFAT-GFP reporter genes}

We established a 2D3 cells in which the signals from transduced TCRs activated the NFAT, followed by the GFP expression as a selection marker for appropriately TCR-transduced cells (Figure 1A). Jurkat-76, a TCR $\alpha / \beta$ negative sub-line of Jurkat (CD8 ${ }^{-} \mathrm{T}$ lymphoma cell line) was thought to be an ideal candidate as a source of the platform cell line because it could not produce endogenous TCRs and thus because transduced TCRs would be well expressed without competition with endogenous TCRs. Therefore, we transduced Jurkat- 76 cells with hCD8 gene and established J76.7 cell line, and finally established $\mathrm{CD}^{+}{ }^{+} \mathrm{D} 3$ cell line by the transducing the $\mathrm{J} 76.7$ cells with NFAT-GFP reporter gene. 2D3 cells did not express CD3 molecules on the cell surface because of lack of their endogenous TCR expression (Figure 1B), and strongly expressed GFP in the majority of cells when they were stimulated with Phorbol 12-myristate 13-acetate (PMA)/ Ionomycin to activate NFAT (Figure 1C). Both expression of hCD8 and NFAT-GFP reporter genes was stable and long-lasting (data not shown). Thus, we succeeded in the establishment of 2D3 cell line suitable for evaluating the expression and function of CTL-derived TCRs.

\section{D3 is a platform cell line for efficient and precise evaluation of the expression and function of transduced TCRs}

To confirm that 2D3 cell line could be a platform cell line suitable for the evaluation of the expression and function of transduced TCRs, 2D3 cells were transduced with lentiviral vector encoding B10-TCR, which was the TCR that was isolated and cloned from an HLA-A*24:02-restricted, $\mathrm{WT}_{235}$ peptide-specific CTL clone, B10 [19]. B10-TCR- and mock-transduced 2D3 cells could be monitored by the expression of Venus fluorescent protein. As expected, B10-TCR-transduced $2 \mathrm{D} 3$ cells expressed both CD3 and TCR $\alpha / \beta$ molecules on their surface and were $\mathrm{WT} 1_{235}$ tetramer-positive. In contrast, mock-transduced 2D3 cells expressed neither CD3 molecules nor B10-TCR (Figure 2A). Furthermore, 
B10-TCR-transduced 2D3 cells showed GFP expression in $\mathrm{WT}_{235}$ peptide-concentration dependent manner (Figure $2 \mathrm{~B}$ ). This $\mathrm{WT}_{235}$ peptide concentration-response curve showed that Effective concentration 50 (EC50), which was often used to describe the functional avidity of TCR, was $52.7 \mathrm{nM}$ (95\% confidence interval (CI), 42.3-64.8 nM) for B10-TCR. In general, since TCR functional avidity is determined by several factors such as TCR affinity and quantities of TCR, CD3, and CD8/CD4 molecules, it is easily influenced by cell types used for experiments, especially by TCR constructs that regulate expression efficacy [20]. Therefore, to confirm that B10TCR functional avidity was stably evaluable by the 2D3 cells regardless of the difference in B10-TCR constructs, we examined the response of 2D3 cells transduced with codon-optimized $\alpha$-p2A- $\beta$ or $\beta$-p2A- $\alpha$ B10-TCR that was different from original B10-TCR construct but specific to $\mathrm{WT} 1_{235}$ peptide (Figure $2 \mathrm{C}$ ). As expected, EC50 was $50.8 \mathrm{nM}$ and $53.7 \mathrm{nM}$ for codon-optimized $\alpha-\mathrm{p} 2 \mathrm{~A}-\beta$ and $\beta-\mathrm{p} 2 \mathrm{~A}-\alpha$ B10-TCRs, respectively, and similar to that obtained from original B10-TCR construct $(\alpha-\mathrm{p} 2 \mathrm{~A}-\beta)$ transduced 2D3 cells (Figure 2C). Thus, 2D3 cell line
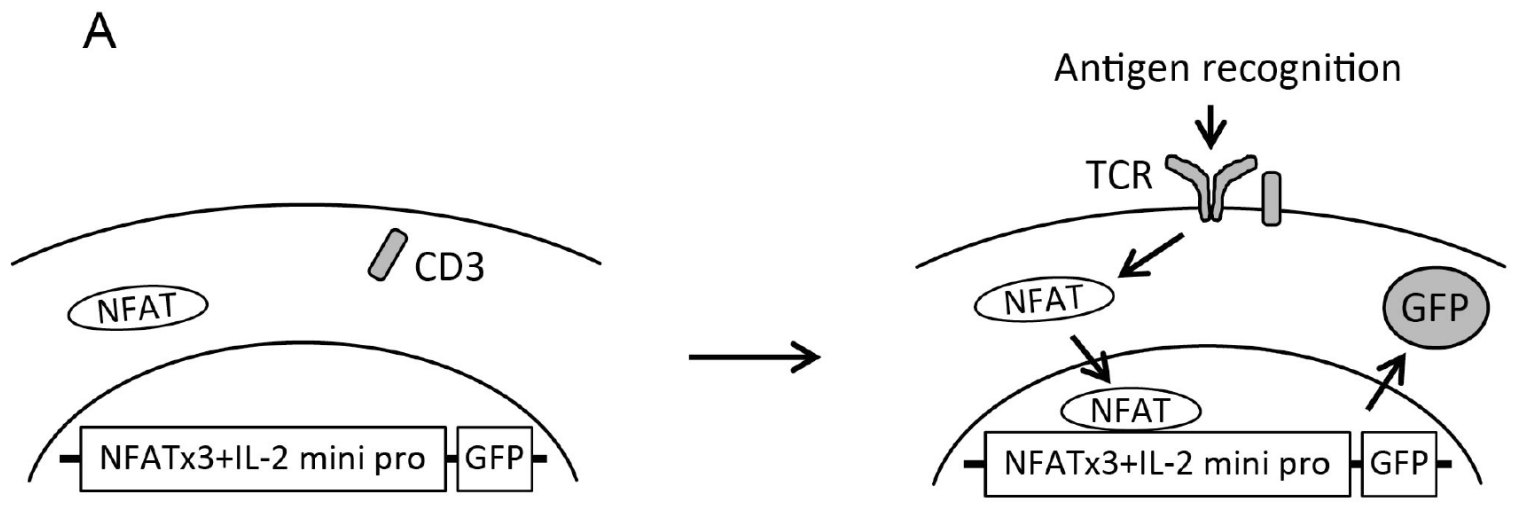

B

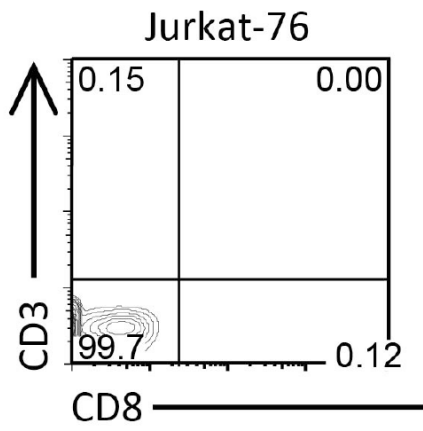

J76.7
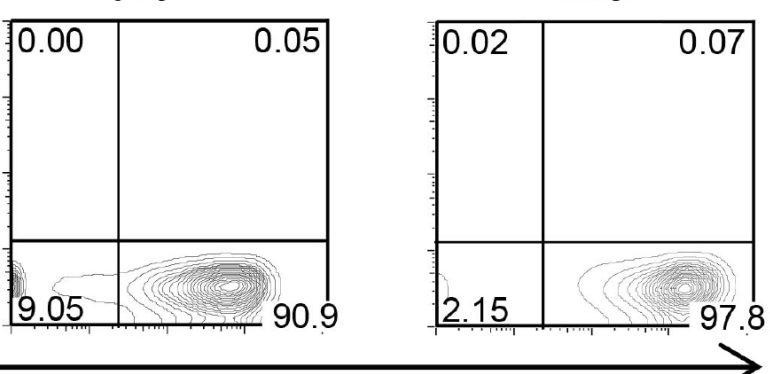

C

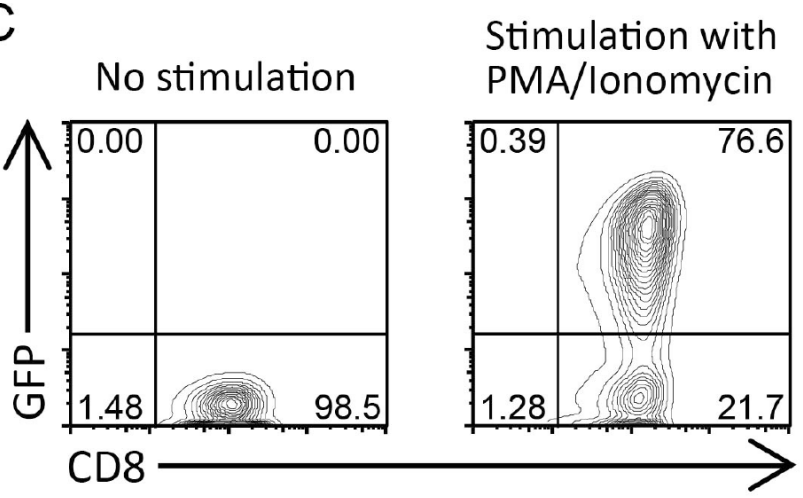

Figure 1: Establishment of $2 D 3$ cell line. (A) Schema of 2D3 cells. The transduction of TCRs into 2D3 cells recruits CD3 onto the cell surface, and appropriate TCR signaling induced by antigen recognition activates the NFAT-GFP reporter gene, followed by GFP production. NFATx3, NFAT-binding sites x3; IL-2 mini pro, IL-2 minimal promoter. (B) Expression of CD3 and CD8 in Jurkat-76, J76.7, and 2D3 cells. Representative contour plots are shown. (C) GFP expression in 2D3 cells after PMA/Ionomycin stimulation. Representative contour plots are shown. 
was thought to be a platform cell line suitable for efficient and precise evaluation of the expression and function of transduced TCRs.

\section{TCR functional avidity evaluated by $2 \mathrm{D} 3$ cells correlate with effector function of the TCR- transduced $\mathrm{CD8}^{+} \mathrm{T}$ cells}

It is well-known that the strength of TCR functional avidity effect the proliferation, cytokine production, and cytotoxicity of TCR-transduced $\mathrm{CD} 8^{+} \mathrm{T}$ cells. Hence, we investigated whether the TCR functional avidity evaluated by 2D3 cells correlated with the function of the TCR-transduced $\mathrm{CD}^{+} \mathrm{T}$ cells. We established four different HLA-A ${ }^{*} 24: 02-$ restricted, modified $\mathrm{WT1}_{235}$ peptide $\left(\mathrm{mWT} 1_{235}\right)$-specific $\mathrm{CD} 8^{+} \mathrm{T}$ cell clones, isolated the TCRs from the clones, and transduced the 2D3 cells with the individual TCRs (Table 1). Four $\mathrm{mWT1}_{235^{-}}$ specific TCR-transduced 2D3 cells expressed GFP in response to $\mathrm{mWT1}_{235}$ and showed individually unique peptide concentration-response curves (Figure 3A). EC50s obtained from $\mathrm{mWT1}_{235}$ concentration-response curves were $43.3 \mathrm{nM}(95 \% \mathrm{CI}, 29.0-65.0 \mathrm{nM})$ for B10TCR, $29.3 \mathrm{nM}(95 \% \mathrm{CI}, 22.1-38.9 \mathrm{nM})$ for TM-H2-TCR, $976 \mathrm{nM}(95 \% \mathrm{CI}, 815-1188 \mathrm{nM})$ for FSK1-TCR, and 1776 nM (95\% CI, 1166-3019 nM) for TM-L1-TCR. Since big difference in EC50 was observed among four $\mathrm{mWT1}_{235}$ -specific TCR-transduced 2D3 cells, we classified these four TCRs into two groups: high-avidity TCRs (B10- and TM-H2-TCRs) and low-avidity TCRs (FSK1- and TML1-TCRs). Next, these four TCRs were transduced into freshly isolated $\mathrm{CD} 8^{+} \mathrm{T}$ cells. High-avidity TCR (B10- and
TM-H2-TCRs)-transduced CD8 ${ }^{+} \mathrm{T}$ cells produced cytokine at much higher frequencies in response to $\mathrm{mWT}_{235}$, compared to low-avidity TCR (FSK1- and TM-L1-TCRs)transduced $\mathrm{CD}^{+} \mathrm{T}$ cells (Figure 3B). It appeared TM-L1TCR-transduced $\mathrm{CD}^{+} \mathrm{T}$ cells rarely produced cytokine in response to $\mathrm{mWT} 1_{23{ }^{5}}$. Furthermore, we examined cell proliferation of B10-TCR, TM-H2-TCR, and FSK1TCR-transduced $\mathrm{CD} 8^{+} \mathrm{T}$ cells by weekly stimulation with $\mathrm{mWT1}_{235}$ (Figure 3C). B10-TCR- and TM-H2-TCRtransduced $\mathrm{CD} 8^{+} \mathrm{T}$ cells remarkably expanded by day 28, whereas FSK1-TCR-transduced $\mathrm{CD}^{+} \mathrm{T}$ cells could not expand regardless of the repeated stimulation with $\mathrm{mWT1}_{235}$. These results demonstrated that TCR functional avidity evaluated by using $2 \mathrm{D} 3$ cells positively correlated with effector functions of the TCR-transduced $\mathrm{CD} 8^{+} \mathrm{T}$ cells.

Next, we determined that the TCR functional avidity evaluated by the 2D3 cells also correlated positively with cytotoxicity of the TCR-transduced $\mathrm{CD}^{+} \mathrm{T}$ cells against HLA-A*24:02-positive, WT1expressing leukemic cells. Since the WT1-expressing leukemic cells expressed natural $\mathrm{WT}_{235}$ peptide $\left(\mathrm{nWT1} 1_{235}\right)$, the functional avidity of the B10-TCR- or TM-H2-TCR-transduced $\mathrm{CD} 8^{+} \mathrm{T}$ cells was evaluated by the $2 \mathrm{D} 3$ cells in response to the $\mathrm{nWT} 1_{235}$, instead of $\mathrm{mWT1}_{235}$ (Figure 3D). The EC50 of B10- and TM-H2TCRs was $62 \mathrm{nM}$ and $180 \mathrm{nM}$, respectively, and that of B10-TCR was approximately three times higher than that of TM-H2-TCR. As shown in Figure 3E, B10TCR-transduced $\mathrm{CD} 8^{+} \mathrm{T}$ cells could lyse HLA-A*24:02positive, WT1-expressing leukemic cells, while TMH2-TCR-transduced CD8 ${ }^{+} \mathrm{T}$ cells could not lyse them. These results showed the positive correlation between
A

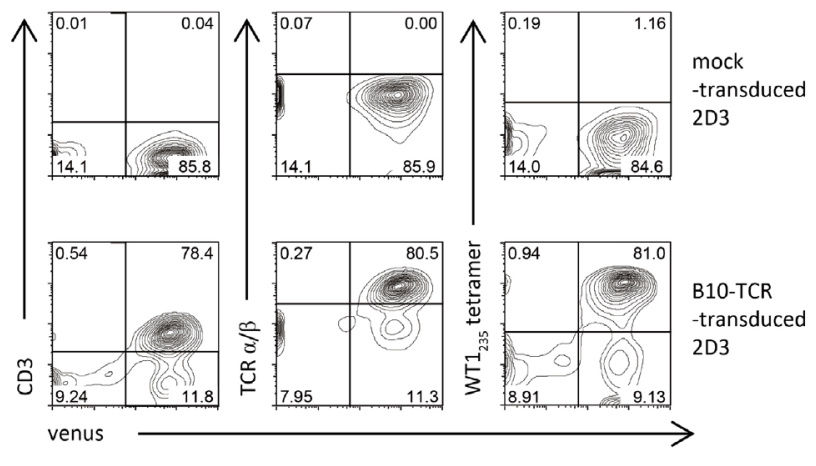

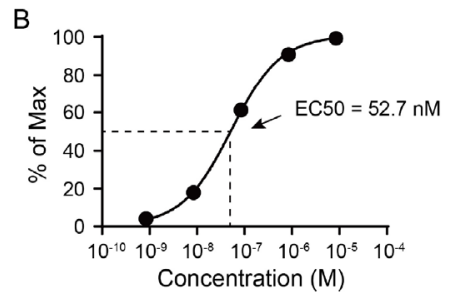

C

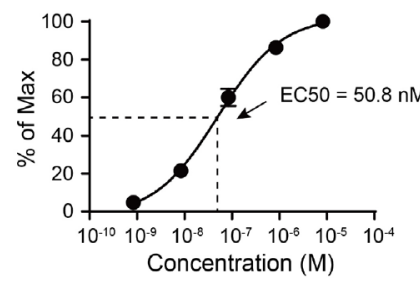

Figure 2: Evaluation of TCR functional avidity by 2 D3 cells. (A) Expression of CD3 and TCR in B10-TCR-transduced 2D3 cells. The $2 \mathrm{D} 3$ cells were stained with anti-CD3, anti-TCR $\alpha / \beta \mathrm{mAbs}$, and $\mathrm{WT} 1_{235}$ tetramer. Representative contour plots are shown. (B, C) Peptide concentration-response curves in 2D3 cells transduced with three different B10-TCR constructs. The 2D3 cells were stimulated with titrated concentration of modified $\mathrm{WT} 1_{235}$ peptide $\left(\mathrm{mWT}_{235}\right)$. Y-axis represents the frequency $(\%$ of max) of GFP-positive cells in 2D3 cells. (B) Peptide concentration-response curve of original $\alpha-p 2 A-\beta$ B10-TCR-transduced 2 D3 cells. (C) Peptide concentrationresponse curves of codon-optimized $\alpha-\mathrm{p} 2 \mathrm{~A}-\beta$ (left) and $\beta$-p2A- $\alpha$ (right) B10-TCR-transduced $2 \mathrm{D} 3$ cells. All data are mean value \pm SEM $(n=3)$. All data are normalized as a percent of maximal frequency of GFP-positive cells. 
Table 1: Identification of WT1 ${ }_{235}$-specific TCRs derived WT1 ${ }_{235}$-specific clones

\begin{tabular}{|c|c|c|c|c|c|c|c|c|c|c|c|c|c|c|c|c|c|c|c|c|c|}
\hline TCR & & $\mathrm{V}$ region & $D$ region & $\mathrm{J}$ region & & & & & & & R3 & $\mathrm{imi}$ & 0 a & d s & uen & & & & & & \\
\hline \multirow{2}{*}{$\mathrm{B} 10$} & $\alpha$ & TRAV27"01 & - & TRAJ28*01 & $\mathrm{C}$ & $\mathrm{A}$ & G & $\mathrm{P}$ & $\mathrm{L}$ & $\mathrm{S}$ & G & A & $\mathrm{S}$ & $\mathrm{Y}$ & Q & $\mathrm{L}$ & $\mathrm{F}$ & & & & \\
\hline & $\beta$ & TRBV9*01 & TRBD1 ${ }^{*} 01$ & TRBJ2-3*01 & $\mathrm{C}$ & A & $\mathrm{S}$ & $\mathrm{S}$ & $\mathrm{L}$ & W & G & S & $\mathrm{T}$ & $\mathrm{D}$ & $\mathrm{T}$ & Q & $\mathrm{Y}$ & $\mathrm{F}$ & & & \\
\hline \multirow{2}{*}{ TM-H2 } & $\alpha$ & TRAV20*02 & - & TRAJ52*01 & $\mathrm{C}$ & A & V & $\mathrm{R}$ & G & G & $\mathrm{R}$ & A & G & G & $\mathrm{T}$ & $\mathrm{S}$ & $\mathrm{Y}$ & $\mathrm{G}$ & $V$ & L $\quad \mathrm{T}$ & $\mathrm{F}$ \\
\hline & $\beta$ & TRBV9*01 & TRBD2* 01 & TRBJ2-3*01 & $\mathrm{C}$ & $\mathrm{A}$ & $\mathrm{S}$ & $\mathrm{S}$ & $\mathrm{V}$ & $\mathrm{F}$ & G & $\mathrm{S}$ & $\mathrm{S}$ & $\mathrm{T}$ & $\mathrm{D}$ & $\mathrm{T}$ & Q & $\mathrm{Y}$ & $\mathrm{F}$ & & \\
\hline \multirow{2}{*}{ FSK1 } & $\alpha$ & TRAV19*01 & - & TRAJ26*01 & $\mathrm{C}$ & $\mathrm{A}$ & $\mathrm{L}$ & $\mathrm{S}$ & A & A & $\mathrm{Y}$ & G & Q & $\mathrm{N}$ & $\mathrm{F}$ & V & $\mathrm{F}$ & & & & \\
\hline & $\beta$ & TRBV6-5*01 & TRBD1*01 & TRBJ2-1*01 & $\mathrm{C}$ & A & $\mathrm{S}$ & $\mathrm{S}$ & $\mathrm{Y}$ & G & K & G & $\mathrm{L}$ & $\mathrm{Y}$ & $\mathrm{N}$ & $\mathrm{E}$ & Q & F & 1 & & \\
\hline \multirow{2}{*}{ TM-L1 } & $\alpha$ & TRAV17"01 & - & TRAJ43*01 & $\mathrm{C}$ & A & $\mathrm{T}$ & $\mathrm{D}$ & $\mathrm{P}$ & G & $\mathrm{Y}$ & $\mathrm{N}$ & $\mathrm{N}$ & $\mathrm{D}$ & M & $\mathrm{R}$ & $\mathrm{F}$ & & & & \\
\hline & $\beta$ & TRBV20-1*01 & TRBD2* 02 & TRBJ2-2*01 & $\mathrm{C}$ & $\mathrm{S}$ & A & $\mathrm{R}$ & G & Q & $\mathrm{R}$ & E & $\mathrm{L}$ & $\mathrm{S}$ & G & $\mathrm{E}$ & $\mathrm{L}$ & $\mathrm{F}$ & $\mathrm{F}$ & & \\
\hline
\end{tabular}

the TCR functional avidity evaluated by $2 \mathrm{D} 3$ cells and the cytotoxicity against HLA-A*24:02-positive, WT1expressing leukemic cells.

Taken together, these findings indicated that TCR functional avidity evaluated by 2D3 cells was clearly and positively correlated with the effector functions such as proliferation, cytokine production, and cytotoxicity of the TCR-transduced $\mathrm{CD}^{+} \mathrm{T}$ cells regardless of whether the TCR specificity was for natural or modified WT1 $1_{235}$ peptide.
A

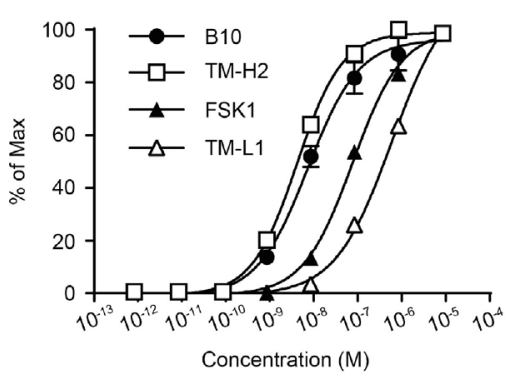

C

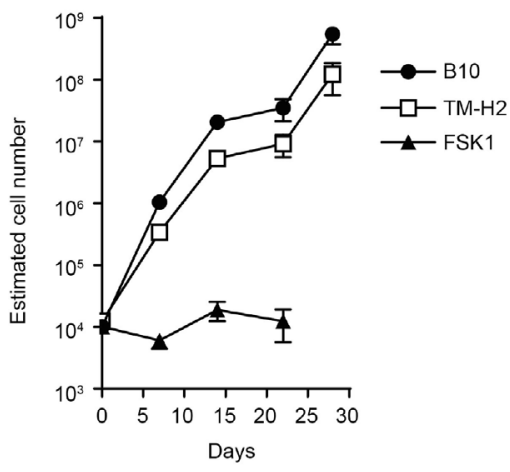

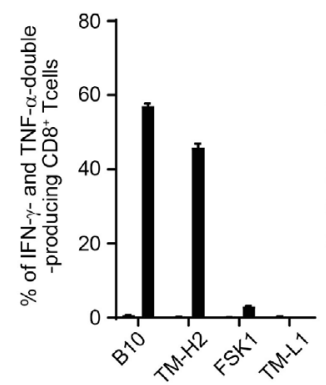
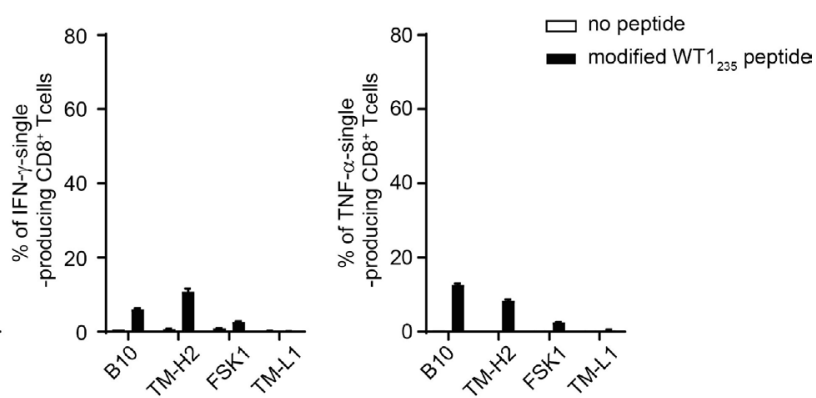

D

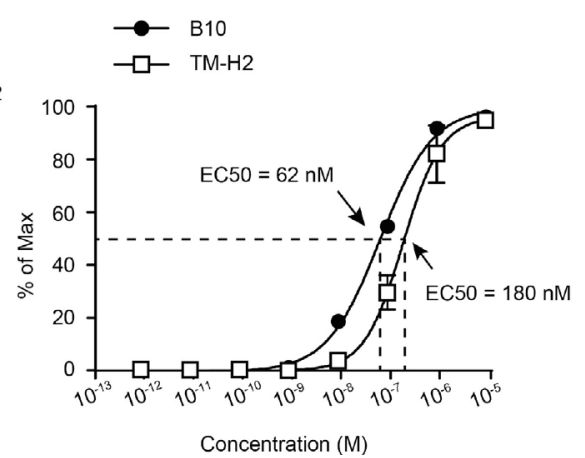

E

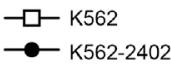

B10-transduced CTLs

TM-H2-transduced CTLs

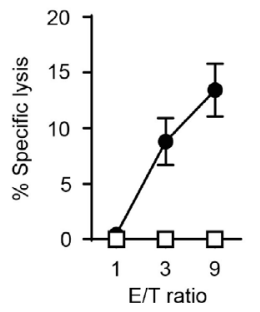

Figure 3: Correlation between TCR functional avidity and effector functions in the TCR-transduced CD8 $^{+} \mathbf{T}$ cells.

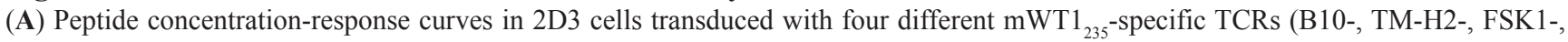
and TM-L1-TCRs) for the stimulation with titrated concentration of $\mathrm{mWT}_{235}$. Y-axis represents the frequency ( $\%$ of max) of GFP-positive cells in 2D3 cells. (B) Cytokine production of $\mathrm{mWT1}_{235}$-specific TCR-transduced CD8 ${ }^{+} \mathrm{T}$ cells stimulated with $1 \mu \mathrm{g} / \mathrm{ml}$ of $\mathrm{mWT} 1_{235}$. Frequencies of IFN- $\gamma$-single-, TNF- $\alpha$-single-, and IFN- $\gamma$ and TNF- $\alpha$-double-producing CD $8^{+}$T cells are shown. (C) Proliferation of WT1specific TCR-transduced CD8 ${ }^{+} \mathrm{T}$ cells. $\mathrm{CD} 8^{+} \mathrm{T}$ cells $\left(5 \times 10^{5}\right.$ cells $)$ were weekly stimulated with $\mathrm{mWT} 1_{235}$, and the estimated number of the WT1-specific TCR-transduced $\mathrm{CD}^{+} \mathrm{T}$ cells was calculated every week. All data are mean values \pm SEM $(n=3)$. (D) Peptide concentration-response curves in $2 \mathrm{D} 3$ cells transduced with $\mathrm{mWT} 1_{235}$-specific B10- or TM-H2-TCR for the stimulation with titrated concentration of $n W T 1_{235}$. It should be noted that peptide used for making the peptide concentration-response curve was mWT1 ${ }_{235}$ for (A) and $\mathrm{nWT}_{235}$ for (D). (E) Cytotoxic activity of B10-TCR or TM-H2-TCR-transduced CD8 ${ }^{+} \mathrm{T}$ cells against WT1-expressing leukemic cells. Assay for cytotoxic activity was performed repeatedly and the representative results are shown. All data are replicate measurements and represent mean values \pm SEM. 


\section{DISCUSSION}

In the present study, we successfully established 2D3 cell line as a platform cell line to efficiently evaluate the function of TCRs. Actually, we demonstrated the clear correlation between TCR functional avidities evaluated by the 2D3 cells and effector functions such as cell proliferation, cytokine production, and cytotoxicity of the TCR-transduced CTLs.

To our knowledge, there is no standard method to evaluate simply the functional avidity of human TCRs. $\mathrm{T}$ cell lines (ex. 58 $\alpha^{-} \beta$, TG40, or Jurkat) and T cells are often used as a platform cell for the evaluation of functional avidities of transduced TCRs, such as cytokine production, killing activity, and phosphorylation of proteins downstream of TCR signaling [21, 22]. Here is a question-are functional avidities evaluated by using these cells? Since mouse T cell lines, $58 \alpha \alpha^{-}$and TG40 express CD3 molecule, human transduced TCRs are expressed on the cell surface with mouse CD3 molecule. However, it is unknown whether the complex of human TCRs and mouse CD3 can induce normal TCR signaling. Indeed, Cohen et al. reported that binding stability between human TCRs and mouse CD3 differed from that between human TCRs and human CD3 [23]. Nagai et al. used TCR-negative Jurkat/MA cells [24] that expressed only CD8 $\alpha$ molecule to monitor TCR signaling [25] because CD $8 \alpha$ could be expressed as CD $8 / \alpha$ homodimers, which could bind to MHC class I molecule, without CD8 $\beta$ on the cell surface. On the other hand, it is well-known that $\mathrm{CD} 8 \beta$ associates with only CD8 $\alpha$ and cannot be expressed alone on the cell surface. Although both CD8 $\alpha / \alpha$ and $\operatorname{CD} 8 \alpha / \beta$ could express on the surface, there is difference in the binding ability to MHC class I molecules between $\mathrm{CD} 8 \alpha / \alpha$ and $\mathrm{CD} 8 \alpha / \beta$ [26]. In addition, $\mathrm{CD} 8 \beta$ intracellular domain promotes association of lymphocytespecific protein kinase (Lck) and LAT with surface CD8 complexes [27]. Of course, almost all mature $\mathrm{CD}^{+} \mathrm{T}$ cells express CD $8 \alpha / \beta$ heterodimer in vivo. Therefore, 2D3 cell line, which expresses CD $\alpha / \beta$ heterodimer, is a suitable platform cell line to assess TCR functional avidity. Furthermore, since 2D3 cell line is deficient in endogenous TCR expression, only transduced TCRs can be expressed on 2D3 cell surface without mispairing with endogenous TCRs. Interestingly, it has been shown that $\mathrm{T}$ cell recognition of $\mathrm{pMHC}$ can be increased up to 50 -fold after priming with the same pMHC [28]. In addition, functional avidity maturation of CTLs can occur through the change of TCR clustering of various molecules such as lipid raft, Lck, and CD3 without the selection of higher affinity TCR during early stage of viral infection [29]. In addition, the same mechanism can also induce the inability of $\mathrm{CD}^{+} \mathrm{T}$ cells for the recognition of pMHC [30]. Taken together, TCR functional avidity of human $\mathrm{T}$ cells is variable in response to antigen stimulation. Therefore, human $\mathrm{T}$ cells are not suitable for platform
$\mathrm{T}$ cells to evaluate TCR functional avidities, whereas the 2D3 cells are convenient for the evaluation of TCR functional avidities because of its functional stabilities.

Previous studies demonstrated that TCR functional avidity determined $\mathrm{T}$ cell fate. It is well-known that in Th1/Th2 polarization, weak TCR signaling favors Th2 differentiation and stronger one induces Th1 differentiation [31-33]. In addition, the difference in TCR functional avidity to self-antigens also has an effect on memory/effector T cell development. Allen PM and his colleagues reported that the magnitude of secondary response in Listeria-specific $\mathrm{T}$ cells was determined by the strength of TCR functional avidity to self-antigen $[34,35]$. Furthermore, we previously demonstrated that WT1-specific $\mathrm{CD}^{+} \mathrm{T}$ cells with high-avidity TCR to WT1 peptide easily differentiated into effector T cells in TCR-retrogenic mice [36]. However, it remains unclear how TCR avidity controls $\mathrm{T}$ cell responses and their fate, especially memory/effector differentiation. Since TCRstimulation of quiescent $\mathrm{T}$ cells such as naïve and memory $\mathrm{T}$ cells induces metabolic shift from catabolic to anabolic energy production, it may be speculated that the strength of TCR avidity finely regulates the metabolic condition that determines T cell differentiation [37]. Primary human T cells are not suitable for the evaluation of the role of TCR avidity in the $\mathrm{T}$ cell functional differentiation because they are heterogeneous and are difficult to keep the cells viable for long term after transduction of TCR genes. On the other hand, Jurkat cell line, which is a parent cell line of 2D3 cell line, is stable to viability and can respond to TCR signals. Jurkat cells can form lipid raft [38], like primary human $\mathrm{T}$ cells, and increase CD3 $\zeta$ and ERK phosphorylation through cholesterol removal [39]. Therefore, it appears that Jurkat cells functionally mimic primary human $\mathrm{T}$ cells, and thus 2D3 cell line should be useful for the study of how TCR avidity controls $\mathrm{T}$ cell responses and their fate.

Since 2D3 cells has a GFP, instead of luciferase, as a reporter gene, we can easily sort the activated TCRtransduced 2D3 cells by using GFP-positivity as an indicator and examine the molecules associated with the signals from the transduced TCR.

In conclusion, we demonstrate a novel platform cell line as a useful tool to evaluate efficient and precise TCR functional avidity for developing TCR-based immunotherapy.

\section{MATERIALS AND METHODS}

\section{Cell lines}

Human T-cell acute leukemia cell line Jurkat-76 [40] deficient in endogenous TCR expression was kindly provided by Prof Hans J Stauss (UCL Cancer Institude, London, UK). Human chronic myelogenous leukemia cell lines, K562 and HLA-A 24:02 gene-transduced $\mathrm{K} 562$, named K562-2402 were kindly gifted from 
Yoshiki Akatsuka (Aichi Cancer Center Research, Aichi, Japan). Transporter associated with antigen processing (TAP)-deficient and HLA-A*24:02-positive cell line, T2-2402 was kindly provided by Kiyotaka Kuzushima (Aichi Cancer Center Research, Aichi, Japan). All cell lines were cultured in RPMI 1640 (Nacalai Tesque Inc., 30264-56) with 10\% heat inactivated fetal bovine serum (FBS) (SIGMA, 172012-500 ML) and 1\% penicillin/ streptomycin (Nacalai Tesque Inc., 26253-84). Lenti-X ${ }^{\text {TM }}$ $293 \mathrm{~T}$ cell lines were purchased by Clontech Laboratories, Inc. (632180) and were cultured in Dulbecco's modified Eagle's medium (DMEM) containing $4.5 \mathrm{mg} / \mathrm{ml}$ glucose (Nacalai Tesque Inc., 08458-16) with 10\% heat inactivated FBS. Human $\mathrm{CD}^{+} \mathrm{T}$ cells were isolated from peripheral blood mononuclear cells using the magnetic BD IMag Cell Separation System according to the manufacturer's instructions (BD Biosciences Pharmingen, 557941) after written informed consent was obtained from healthy volunteers. T cells were cultured in X-VIVO ${ }^{\mathrm{TM}} 15$ (Lonza, 04-418Q) supplemented with 10\% heat inactivated human AB serum (GemCell, Gemini, BioProducts, 100-512) and interleukin (IL)-2 (Imunace35, Shionogi \& Co., LTD) at appropriate concentration.

\section{Peptides, antibodies, and reagents}

Natural WT1 $_{235}$ peptide $\left(\mathrm{nWT}_{235}\right.$ peptide; CMTWNQMNL) and modified $\mathrm{WT}_{235}$ peptide $\left(\mathrm{mWT}_{235}\right.$ peptide; CYTWNQMNL) were synthesized by SigmaAldrich Co., LLC. and Peptide Institute, Inc., respectively. For flow cytometric analysis, the following mAbs were used: anti-CD3-eFluor 450 (UCHT1, 48-0038-42), anti-TCR $\alpha / \beta$-Phycoerythrin (PE) (IP26, 12-9986-42), anti-Interferon (IFN)- $\gamma$-PE (4S.B3, 12-7319-82) and anti-Tumor Necrosis Factor (TNF)- $\alpha$-Allophycocyanine (APC) (MAb11, 17-7349-82) purchased from eBioscience and anti-CD8-APC-Cy7 (RPA-T8, 250088-T025) purchased from Tonbo Biosciences. PE-labeled HLA-A*24:02 modified WT1 ${ }_{235-243}$ tetramer $\left(\mathrm{WT}_{235}\right.$ tetramer) was purchased from MBL Co., Ltd. (TS-M014-1). RetoroNectin (TaKaRa Bio Co., T100A) and anti-CD3 mAb (OKT-3, Tonbo Biosciences, 40-0037-U500) were used at concentrations of $20 \mu \mathrm{g} / \mathrm{ml}$ and $2 \mu \mathrm{g} / \mathrm{ml}$, respectively, to stimulate human $\mathrm{CD}^{+}$ $\mathrm{T}$ cells. NFAT-GFP reporter plasmid [41] was kindly provided by Prof. Takashi Saito (Riken Research Center for Allergy and Immunology, Yokohama, Japan). PMA (Sigma-Aldrich, P8139-1MG) and Ionomycin (SigmaAldrich, I0634) were used at concentrations of $25 \mathrm{ng} / \mathrm{ml}$ and $1 \mu \mathrm{g} / \mathrm{ml}$, respectively.

\section{Establishment of $2 D 3$ cell line}

Two hundred thousand Jurkat-76 cells were subjected to electroporation with hCD $8 \alpha-\mathrm{E} 2 \mathrm{~A}-$ hCD8 $\beta$-encoding pcDNA3.1/Zeo $(+)$ using the Neon transfection system (Thermo Fisher Scientific Inc., MPK5000) according to the manufacturer's guidelines. hCD $8 \alpha$-E2A-hCD $8 \beta$ construct was kindly provided by Prof Hans J Stauss. CD8-transduced Jurkat-76 cells were single-cell sorted into 96-well round-bottom plates and stably hCD8 $\alpha / \beta$-expressing Jurkat-76 cell line, named J76.7 was successfully established. Two hundred thousand J76.7 cells were transduced with NFAT-GFP reporter plasmid by electroporation followed by single cell sort. A single-cell-derived cell line capable of highly expressing GFP protein only when stimulated with PMA/Ionomycin was established as 2D3 cell line.

\section{Cloning of full-length TCR $\alpha$ and TCR $\beta$ chain genes from WT1-specific $T$ cell clone and lentiviral vector construction}

HLA-A*24:02-restricted, WT1 ${ }_{235}$-specific B10TCR was isolated previously [19]. FSK1-TCR, TM-H2TCR, and TM-L1-TCR were isolated from distinct HLA$\mathrm{A}^{*}$ 24:02-restricted $\mathrm{WT}_{235}$-specific $\mathrm{CD}^{+} \mathrm{T}$ cell clones and identified as described previously [42]. In order to transduce $\mathrm{WT}_{235}$-specific TCR into CD ${ }^{+} \mathrm{T}$ cells, TCRs ( $\beta$-p2A- $\alpha$ cassettes) were codon-optimized, synthesized by GeneArt (Thermo Fisher), and cloned into CSII-EF-MCSIRES2-Venus lentiviral vector (kindly provided from Drs Hiroyuki Miyoshi and Atsushi Miyawaki, RIKEN, Tsukuba, Japan) with shRNA constructs for endogenous TCR $\alpha / \beta$ constant regions to prevent mispairing between the transduced and endogenous TCRs [17]. Lentivirus particles were obtained from transient transfection of Lenti-X ${ }^{\text {TM }}$ 293T cells with each TCR-encoding lentiviral vector, pCAG-HIVgp, and pCMV-VSV-G-RSV-Rev (kindly provided by Dr H Miyoshi).

\section{Transduction of WT1-specific TCR genes}

To transduce TCR-encoding lentivirus vector into $\mathrm{CD}^{+} \mathrm{T}$ cells, $\mathrm{CD}^{+} \mathrm{T}$ cells were stimulated with RetroNectin- and OKT-3-coated 48-well plate in the presence of IL-2 (40 IU/ml). On the next day, the stimulated $\mathrm{CD}^{+} \mathrm{T}$ cells were spin-infected with lentivirus vector in the presence of polybrene $(10 \mu \mathrm{g} / \mathrm{ml}$, SigmaAldrich, H9268) at $1000 \mathrm{~g}$ for 2 hours at $32^{\circ} \mathrm{C}$. After 6-12 hours, the culture medium was changed into fresh medium supplemented with $10 \%$ heat inactivated human AB serum and IL-2 (100 IU/ml). To establish WT1 ${ }_{235}{ }^{-}$ specific TCR-transduced 2D3 cells, 2D3 cells were transfected with TCR-encoding lentivirus in the presence of polybrene. Venus-positive 2D3 cells were sorted and used for NFAT-GFP reporter assay as described below.

\section{NFAT-GFP reporter assay}

To evaluate the functional avidities of $\mathrm{WT}_{235^{-}}$ specific TCRs, we used 2D3 cell line. In brief, $1 \times 10^{5} \mathrm{~T} 2-$ 
2402 cells and $1 \times 10^{5}$ TCR-transduced 2D3 cells were cocultured in the presence of titrated concentration of WT1 peptide for 6 hours. The cells were washed with Phosphate buffered saline (PBS) (Nacalai Tesque, 14249-95) with $2 \%$ FBS and then measured for the frequency of GFPpositive cells in venus-positive cells using a FACSAria instrument (BD Biosciences). Data were analyzed using FlowJo 7.6.5 software (FlowJo, LLC).

\section{Intracellular cytokine detection assay}

One hundred thousand $\mathrm{WT} 1_{235}$-speicifc TCRtransduced $\mathrm{CD}^{+} \mathrm{T}$ cells were co-cultured with $5 \times 10^{4}$ $\mathrm{T} 2-2402$ in the presence of $10 \mu \mathrm{g} / \mathrm{ml}$ of Brefeldin A (Sigma-Aldrich) and $1 \mu \mathrm{g} / \mathrm{ml}$ of natural $\mathrm{WT} 1_{235}$ peptide or modified $\mathrm{WT}_{235}$ peptide for 4 hours. After cell surface marker staining, intracellular cytokine assay was performed as described previously [42].

\section{Proliferation assay}

$\mathrm{CD}^{+} \mathrm{T}$ cells were transduced with $\mathrm{WT}_{235}$-specific TCRs as described above, and the transduced $\mathrm{CD} 8^{+} \mathrm{T}$ cells $\left(5 \times 10^{5}\right)$ were stimulated by the co-culture with irradiated $\mathrm{mWT}_{235}$ peptide-pulsed autologous PBMCs. Seven days later, the expanded cells were harvested, counted by trypan blue, and measured for the frequency of WT1 $1_{235}$-specific TCR-transduced $\mathrm{CD}^{+} \mathrm{T}$ cells using tetramer assay. Five hundred thousand cells out of the expanded cells were restimulated and re-expanded as described above. The series of experiments was three times repeated. The number of $\mathrm{WT}_{235}$-specific TCR-transduced $\mathrm{CD}^{+} \mathrm{T}$ cells was calculated as the number of venus ${ }^{+} \mathrm{WT}_{235}$ tetramer ${ }^{+}$cells accumulated.

\section{${ }^{51} \mathrm{Cr}$ release assay}

${ }^{51} \mathrm{Cr}$ release assays were performed as previously described [19].

\section{Statistical analysis}

The statistical analysis and the calculation of EC50 values were performed with GraphPad Prism 7 (GraphPad Prism Software, San Diego, CA, USA).

\section{Abbreviations}

TCR: T-cell receptor; GFP: green fluorescent protein; NFAT: nuclear factor of activated T cells; HLA: human leukocyte antigen; WT1: Wilms' tumor gene 1; CTL: cytotoxic T lymphocyte; TAA: tumor-associated antigen; Th cells: $\mathrm{CD}^{+}$helper T cells; MHC: major histocompatibility complex; LAT: linker for activation of T cells; ERK: extracellular signal-regulated kinase; TAP: transporter associated with antigen processing; FBS: fetal bovine serum; DMEM: Dulbecco's modified Eagle's medium; IL-2: interleukin 2; PE: Phycoerythrin; IFN: Interferon; TNF: Tumor Necrosis
Factor; APC: Allophycocyanine; PMA: phorbol 12-myristate 13-acetate; EC50: Effective concentration 50; CI: confidence interval; Lck: lymphocyte-specific protein kinase.

\section{Author contributions}

FF and HS designed the project; SM and FF designed the experiments; SM, FF, KK, YK, MI, NA, and YN performed the experiments; SM, FF, YK, and MI analyzed the data; SM, FF, and HS wrote the manuscript; $\mathrm{HN}, \mathrm{SN}, \mathrm{JN}, \mathrm{NH}, \mathrm{AT}, \mathrm{YOk}$, and YOj provided advice.

\section{ACKNOWLEDGMENTS}

We would like to thank Dr. Hiroyuki Miyoshi (RIKEN BioResource Center, Tsukuba, Japan) for providing vectors for lentivirus production. We also thank staff at the Center for Medical Research and Education, Graduate School of Medicine, Osaka University, for technical support.

\section{CONFLICTS OF INTEREST}

All authors have no financial conflicts of interest.

\section{FUNDING}

This research was supported, in part, by JSPS KAKENHI Grant Numbers JP15K18446, JP17K07216, JP26430162, and JP17K07215. Department of Cancer Immunology is a department in collaboration with Otsuka Pharmaceutical Co., Ltd. and is supported with a grant from the company.

\section{REFERENCES}

1. Hunder NN, Wallen H, Cao J, Hendricks DW, Reilly JZ, Rodmyre R, Jungbluth A, Gnjatic S, Thompson JA, Yee C. Treatment of metastatic melanoma with autologous CD4+ T cells against NY-ESO-1. N Engl J Med. 2008; 358 : 2698-703. https://doi.org/10.1056/NEJMoa0800251.

2. Dudley ME, Wunderlich JR, Yang JC, Sherry RM, Topalian SL, Restifo NP, Royal RE, Kammula U, White DE, Mavroukakis SA, Rogers LJ, Gracia GJ, Jones $\mathrm{SA}$, et al. Adoptive cell transfer therapy following nonmyeloablative but lymphodepleting chemotherapy for the treatment of patients with refractory metastatic melanoma. J Clin Oncol. 2005; 23:2346-57. https://doi.org/10.1200/ JCO.2005.00.240.

3. Quezada SA, Simpson TR, Peggs KS, Merghoub T, Vider J, Fan X, Blasberg R, Yagita H, Muranski P, Antony PA, Restifo NP, Allison JP. Tumor-reactive CD4(+) T cells develop cytotoxic activity and eradicate large established melanoma after transfer into lymphopenic hosts. J Exp Med. 2010; 207:637-50. https://doi.org/10.1084/jem.20091918. 
4. Schumacher TN, Schreiber RD. Neoantigens in cancer immunotherapy. Science. 2015; 348:69-74. https://doi. org/10.1126/science.aaa4971.

5. Tran E, Turcotte S, Gros A, Robbins PF, Lu YC, Dudley ME, Wunderlich JR, Somerville RP, Hogan K, Hinrichs CS, Parkhurst MR, Yang JC, Rosenberg SA. Cancer immunotherapy based on mutation-specific CD4+ T cells in a patient with epithelial cancer. Science. 2014; 344:641-5. https://doi.org/10.1126/science.1251102.

6. Castle JC, Kreiter S, Diekmann J, Lower M, van de Roemer N, de Graaf J, Selmi A, Diken M, Boegel S, Paret C, Koslowski M, Kuhn AN, Britten CM, et al. Exploiting the mutanome for tumor vaccination. Cancer Res. 2012; 72:1081-91. https://doi.org/10.1158/0008-5472. CAN-11-3722.

7. Matsushita H, Vesely MD, Koboldt DC, Rickert CG, Uppaluri R, Magrini VJ, Arthur CD, White JM, Chen YS, Shea LK, Hundal J, Wendl MC, Demeter R, et al. Cancer exome analysis reveals a T-cell-dependent mechanism of cancer immunoediting. Nature. 2012; 482:400-4. https:// doi.org/10.1038/nature10755.

8. Robbins PF, Lu YC, El-Gamil M, Li YF, Gross C, Gartner J, Lin JC, Teer JK, Cliften P, Tycksen E, Samuels Y, Rosenberg SA. Mining exomic sequencing data to identify mutated antigens recognized by adoptively transferred tumor-reactive T cells. Nat Med. 2013; 19:747-52. https:// doi.org/10.1038/nm.3161.

9. Calis JJ, Rosenberg BR. Characterizing immune repertoires by high throughput sequencing: strategies and applications. Trends Immunol. 2014; 35:581-90. https://doi. org/10.1016/j.it.2014.09.004.

10. Linnemann C, van Buuren MM, Bies L, Verdegaal EM, Schotte R, Calis JJ, Behjati S, Velds A, Hilkmann H, Atmioui DE, Visser M, Stratton MR, Haanen JB, et al. Highthroughput epitope discovery reveals frequent recognition of neo-antigens by CD4 $+\mathrm{T}$ cells in human melanoma. Nat Med. 2015; 21:81-5. https://doi.org/10.1038/nm.3773.

11. Kobayashi E, Mizukoshi E, Kishi H, Ozawa T, Hamana H, Nagai T, Nakagawa H, Jin A, Kaneko S, Muraguchi A. A new cloning and expression system yields and validates TCRs from blood lymphocytes of patients with cancer within 10 days. Nat Med. 2013; 19:1542-6. https://doi. org/10.1038/nm.3358.

12. Schmid DA, Irving MB, Posevitz V, Hebeisen M, PosevitzFejfar A, Sarria JC, Gomez-Eerland R, Thome M, Schumacher TN, Romero P, Speiser DE, Zoete V, Michielin $\mathrm{O}$, et al. Evidence for a TCR affinity threshold delimiting maximal CD8 T cell function. J Immunol. 2010; 184: 4936-46. https://doi.org/10.4049/jimmunol.1000173.

13. Stone JD, Chervin AS, Kranz DM. T-cell receptor binding affinities and kinetics: impact on T-cell activity and specificity. Immunology. 2009; 126:165-76. https://doi. org/10.1111/j.1365-2567.2008.03015.x.

14. Zhong S, Malecek K, Johnson LA, Yu Z, Vega-Saenz de Miera E, Darvishian F, McGary K, Huang K, Boyer J,
Corse E, Shao Y, Rosenberg SA, Restifo NP, et al. T-cell receptor affinity and avidity defines antitumor response and autoimmunity in T-cell immunotherapy. Proc Natl Acad Sci U S A. 2013; 110:6973-8. https://doi.org/10.1073/ pnas. 1221609110.

15. Xiang B, Baybutt TR, Berman-Booty L, Magee MS, Waldman SA, Alexeev VY, Snook AE. Prime-Boost Immunization Eliminates Metastatic Colorectal Cancer by Producing High-Avidity Effector CD8(+) T Cells. J Immunol. 2017; 198:3507-14. https://doi.org/10.4049/ jimmunol.1502672.

16. Laugel B, van den Berg HA, Gostick E, Cole DK, Wooldridge L, Boulter J, Milicic A, Price DA, Sewell AK. Different $T$ cell receptor affinity thresholds and CD8 coreceptor dependence govern cytotoxic $\mathrm{T}$ lymphocyte activation and tetramer binding properties. J Biol Chem. 2007; 282:23799-810. https://doi.org/10.1074/jbc. M700976200.

17. Okamoto S, Mineno J, Ikeda H, Fujiwara H, Yasukawa M, Shiku H, Kato I. Improved expression and reactivity of transduced tumor-specific TCRs in human lymphocytes by specific silencing of endogenous TCR. Cancer Res. 2009; 69:9003-11. https://doi.org/10.1158/0008-5472.CAN-09-1450.

18. Ahmadi M, King JW, Xue SA, Voisine C, Holler A, Wright GP, Waxman J, Morris E, Stauss HJ. CD3 limits the efficacy of TCR gene therapy in vivo. Blood. 2011; 118:3528-37. https://doi.org/10.1182/blood-2011-04-346338.

19. Tamanaka T, Oka Y, Fujiki F, Tsuboi A, Katsuhara A, Nakajima H, Hosen N, Nishida S, Lin YH, Tachino S, Akatsuka Y, Kuzushima K, Oji Y, et al. Recognition of a natural WT1 epitope by a modified WT1 peptide-specific T-cell receptor. Anticancer Res. 2012; 32:5201-9.

20. Leisegang M, Engels B, Meyerhuber P, Kieback E, Sommermeyer D, Xue SA, Reuss S, Stauss H, Uckert W. Enhanced functionality of $\mathrm{T}$ cell receptor-redirected $\mathrm{T}$ cells is defined by the transgene cassette. J Mol Med (Berl). 2008; 86:573-83. https://doi.org/10.1007/s00109-008-0317-3.

21. Cebula A, Seweryn M, Rempala GA, Pabla SS, McIndoe RA, Denning TL, Bry L, Kraj P, Kisielow P, Ignatowicz L. Thymus-derived regulatory $\mathrm{T}$ cells contribute to tolerance to commensal microbiota. Nature. 2013; 497:258-62. https:// doi.org/10.1038/nature12079.

22. Ise W, Kohyama M, Nutsch KM, Lee HM, Suri A, Unanue ER, Murphy TL, Murphy KM. CTLA-4 suppresses the pathogenicity of self antigen-specific $\mathrm{T}$ cells by cellintrinsic and cell-extrinsic mechanisms. Nat Immunol. 2010; 11:129-35. https://doi.org/10.1038/ni.1835.

23. Cohen CJ, Zhao Y, Zheng Z, Rosenberg SA, Morgan RA. Enhanced antitumor activity of murine-human hybrid T-cell receptor (TCR) in human lymphocytes is associated with improved pairing and TCR/CD3 stability. Cancer Res. 2006; 66:8878-86. https://doi.org/10.1158/0008-5472. CAN-06-1450.

24. Scholten KB, Schreurs MW, Ruizendaal JJ, Kueter EW, Kramer D, Veenbergen S, Meijer CJ, Hooijberg E. 
Preservation and redirection of HPV16E7-specific T cell receptors for immunotherapy of cervical cancer. Clin Immunol. 2005; 114:119-29. https://doi.org/10.1016/j. clim.2004.11.005.

25. Nagai K, Ochi T, Fujiwara H, An J, Shirakata T, Mineno J, Kuzushima K, Shiku H, Melenhorst JJ, Gostick E, Price DA, Ishii E, Yasukawa M. Aurora kinase A-specific T-cell receptor gene transfer redirects $\mathrm{T}$ lymphocytes to display effective antileukemia reactivity. Blood. 2012; 119:368-76. https://doi.org/10.1182/blood-2011-06-360354.

26. Sun J, Kavathas PB. Comparison of the roles of CD8 alpha alpha and CD8 alpha beta in interaction with MHC class I. J Immunol. 1997; 159:6077-82.

27. Bosselut R, Kubo S, Guinter T, Kopacz JL, Altman JD, Feigenbaum L, Singer A. Role of CD8beta domains in CD8 coreceptor function: importance for MHC I binding, signaling, and positive selection of CD8+ T cells in the thymus. Immunity. 2000; 12:409-18.

28. Fahmy TM, Bieler JG, Edidin M, Schneck JP. Increased TCR avidity after $\mathrm{T}$ cell activation: a mechanism for sensing low-density antigen. Immunity. 2001; 14:135-43.

29. Slifka MK, Whitton JL. Functional avidity maturation of CD8(+) T cells without selection of higher affinity TCR. Nat Immunol. 2001; 2:711-7. https://doi.org/10.1038/90650.

30. Nagaraj S, Gupta K, Pisarev V, Kinarsky L, Sherman S, Kang L, Herber DL, Schneck J, Gabrilovich DI. Altered recognition of antigen is a mechanism of CD8+ T cell tolerance in cancer. Nat Med. 2007; 13:828-35. https://doi. org/10.1038/nm1609.

31. Constant SL, Bottomly K. Induction of Th1 and Th2 CD4+ T cell responses: the alternative approaches. Annu Rev Immunol. 1997; 15:297-322. https://doi.org/10.1146/ annurev.immunol.15.1.297.

32. Tao X, Grant C, Constant S, Bottomly K. Induction of IL-4producing CD4+ T cells by antigenic peptides altered for TCR binding. J Immunol. 1997; 158:4237-44.

33. van Panhuys N, Klauschen F, Germain RN. T-cell-receptordependent signal intensity dominantly controls CD4(+) T cell polarization In Vivo. Immunity. 2014; 41:63-74. https:// doi.org/10.1016/j.immuni.2014.06.003.

34. Persaud SP, Parker CR, Lo WL, Weber KS, Allen PM. Intrinsic CD4+ $\mathrm{T}$ cell sensitivity and response to a pathogen are set and sustained by avidity for thymic and peripheral complexes of self peptide and MHC. Nat Immunol. 2014; 15:266-74. https://doi.org/10.1038/ni.2822.

35. Weber KS, Li QJ, Persaud SP, Campbell JD, Davis MM, Allen PM. Distinct CD4+ helper T cells involved in primary and secondary responses to infection. Proc Natl Acad Sci U S A. 2012; 109:9511-6. https://doi.org/10.1073/ pnas. 1202408109.

36. Kondo K, Fujiki F, Nakajima H, Yatsukawa E, Morimoto S, Tatsumi N, Nishida S, Nakata J, Oka Y, Tsuboi A, Hosen N, Oji Y, Sugiyama H. An Essential Role of the Avidity of T-Cell Receptor in Differentiation of Self-Antigen-reactive CD8+ T Cells. J Immunother. 2016; 39:127-39. https://doi. org/10.1097/CJI.0000000000000114.

37. Man K, Miasari M, Shi W, Xin A, Henstridge DC, Preston S, Pellegrini M, Belz GT, Smyth GK, Febbraio MA, Nutt $\mathrm{SL}$, Kallies A. The transcription factor IRF4 is essential for TCR affinity-mediated metabolic programming and clonal expansion of T cells. Nat Immunol. 2013; 14:1155-65. https://doi.org/10.1038/ni.2710.

38. Sharma N, Baek K, Phan HTT, Shimokawa N, Takagi M. Glycosyl chains and 25-hydroxycholesterol contribute to the intracellular transport of amyloid beta (Abeta-42) in Jurkat T cells. FEBS Open Bio. 2017; 7:865-76. https:// doi.org/10.1002/2211-5463.12234.

39. Swamy M, Beck-Garcia K, Beck-Garcia E, Hartl FA, Morath A, Yousefi OS, Dopfer EP, Molnar E, Schulze AK, Blanco R, Borroto A, Martin-Blanco N, Alarcon B, et al. A Cholesterol-Based Allostery Model of T Cell Receptor Phosphorylation. Immunity. 2016; 44:1091-101. https://doi. org/10.1016/j.immuni.2016.04.011.

40. Mommaas B, van Halteren AG, Pool J, van der Veken L, Wieles B, Heemskerk MH, Goulmy E. Adult and cord blood T cells can acquire HA-1 specificity through HA-1 T-cell receptor gene transfer. Haematologica. 2005; 90:1415-21.

41. Ohtsuka M, Arase H, Takeuchi A, Yamasaki S, Shiina R, Suenaga T, Sakurai D, Yokosuka T, Arase N, Iwashima M, Kitamura T, Moriya H, Saito T. NFAM1, an immunoreceptor tyrosine-based activation motif-bearing molecule that regulates B cell development and signaling. Proc Natl Acad Sci U S A. 2004; 101:8126-31. https://doi. org/10.1073/pnas.0401119101.

42. Lin Y, Fujiki F, Katsuhara A, Oka Y, Tsuboi A, Aoyama $\mathrm{N}$, Tanii S, Nakajima H, Tatsumi N, Morimoto S, Tamanaka T, Tachino S, Hosen N, et al. HLA-DPB1*05: 01-restricted WT1332-specific TCR-transduced CD4+ T lymphocytes display a helper activity for WT1-specific CTL induction and a cytotoxicity against leukemia cells. J Immunother. 2013; 36:159-70. https://doi.org/10.1097/ CJI.0b013e3182873581. 